\title{
SEED GERMINABILITY AND GRASS BIOLOGY OF MEDICINAL PLANT SALVIA (SALVIA OFFICINALIS L.)
}

\author{
Egamyor Toshboevich Akhmedov \\ Candidate of Biological Sciences, Associate Professor of the Department Medicinal Plants, \\ Tashkent State Agrarian University, Tashkent, Uzbekistan \\ Vakhob Tukhtamishevich Kaysarov \\ Candidate of Biological Sciences, Associate Professor of the Department Medicinal Plants, \\ Tashkent State Agrarian University, Tashkent, Uzbekistan

\section{Munira Zoidovna Yuldasheva} \\ Scientific Researcher, Department of Medicinal Plants, Tashkent State Agrarian University, \\ Tashkent, Uzbekistan
}

Article DOI: https://doi.org/10.36713/epra5276

\begin{abstract}
The article presents the data on seed germination of Salvia officinalis L. in laboratory and field conditions. The mass of 1000 seeds of the plant is 7-8g. It has been revealed that the optimal sowing time for S. officinalis L. is the spring period. At the same time, laboratory and soil germination of freshly harvested seeds of S. officinalis L. constitutes 70-85\%. Plant seeds sprout 15-20 days after sowing. Plant safety in the conditions of Tashkent oasis in the aisles is $70-80 \%$. In the first year of life, plants do not enter the generative phase of development. In recent time, a collection of this plant has been created and methods of mass reproduction, as well as agricultural measures, are being studied.
\end{abstract}

KEYWORDS: Salvia officinalis L., field, generative, reproduction, seeds, biology, raw material.

\section{INTRODUCTION}

Today, the naturalization of medicinal materials used in the pharmaceutical industry is one of the most crucial issues. In this regard, a number of works are being carried out by scientists in our country. At present, more than 30 medicinal plants are grown to meet the needs of pharmaceutical companies for medicinal plant raw materials. However, Salvia officinalis L. is relatively rare among the cultivated medicinal plants.

Salvia - is a plant belonging to the family of Lamiaceae. There are 500 species of this genus in the world and 16 species in Uzbekistan. In ethnoscience and modern medicine, this plant is widely used as a healing plant. This is because in the foreign pharmaceutical and perfumery industry, the production of various medicine from its topsoil raw materials has been established [2].

"The Action Strategy" of the Republic of Uzbekistan for 2017-2021 sets a number of tasks in this field. It is important to select medicinal and food plants, taking into account their biological properties, to develop and implement the technology for their cultivation [6].

For this purpose, a collection of this plant has been created on the experimental plot of Tashkent State Agrarian University, and the bioecological features of the plant are being studied in detail.

The purpose of the research work: Study of seed germinability of $S$. officinalis L. medicinal plant in laboratory and field conditions. 


\section{EPRA International Journal of Research and Development (IJRD)

Tasks of the research work: To determine seed germination in laboratory and field conditions. To study generative reproduction methods and bioecological features.

\section{MATERIALS AND METHODS}

The medicinal plant $S$. officinalis belongs to the family Lamiaceae. There are 500 species of this genus in the world and 16 species in Uzbekistan. The species of Salvia grow on mountain cliffs, from the slopes to the middle of the mountains, in the hills, gardens and fields. Salvia is a perennial herb, it reaches $50-100 \mathrm{~cm}$. Stem has erect shape, hairy, quadrangular. The leaves are ovoid, heart-shaped, serrated, are arranged oppositely along the square stems. The foliage on anterior roots and below the stem are elongated in the petiole, while the foliage at the top of the stem are without petiole. The flowers are pink and purple in colour, short-stemmed. The flowers are usually tubular with two lips and only two stamens and are borne in terminal inflorescences. They produce four nutlet fruits. [5]. The seed of this plant is the object of the study.

The methods of research: Field experiments were conducted by specialists and researchers of the Botanical Garden of the Academy of Sciences of Uzbekistan,
Uzpharmsanoat SJSC in 2015 on the basis of guidelines. In determining the viability of the seeds under laboratory conditions, they were sown in a Petri dish on 4 replications and tested and determined on a percentage. In the field, seeds soaked in the ash solution for 1 day were sown in 5 rows of by 100 seeds and calculated as a percentage $[1,4]$.

\section{RESULTS AND DISCUSSION}

Seed germinability. It is known that the germination of seeds is a key indicator in the formation of plant crop areas. In this purpose, our scientific research has studied methods of propagation from plant seeds.

The fruit of the medicinal plant Salvia consists of 4 nuts. The seeds are 2,2-3 mm long, with a smooth surface, in dark brown colour. The weight of 1000 seeds makes 7-8 g.

To study seed germination under laboratory conditions, bibulous paper was laid on a Petri dish and seeds were sown in it (100 pcs.), germination was fully observed after 16-20 days and lasted 35-40 days.

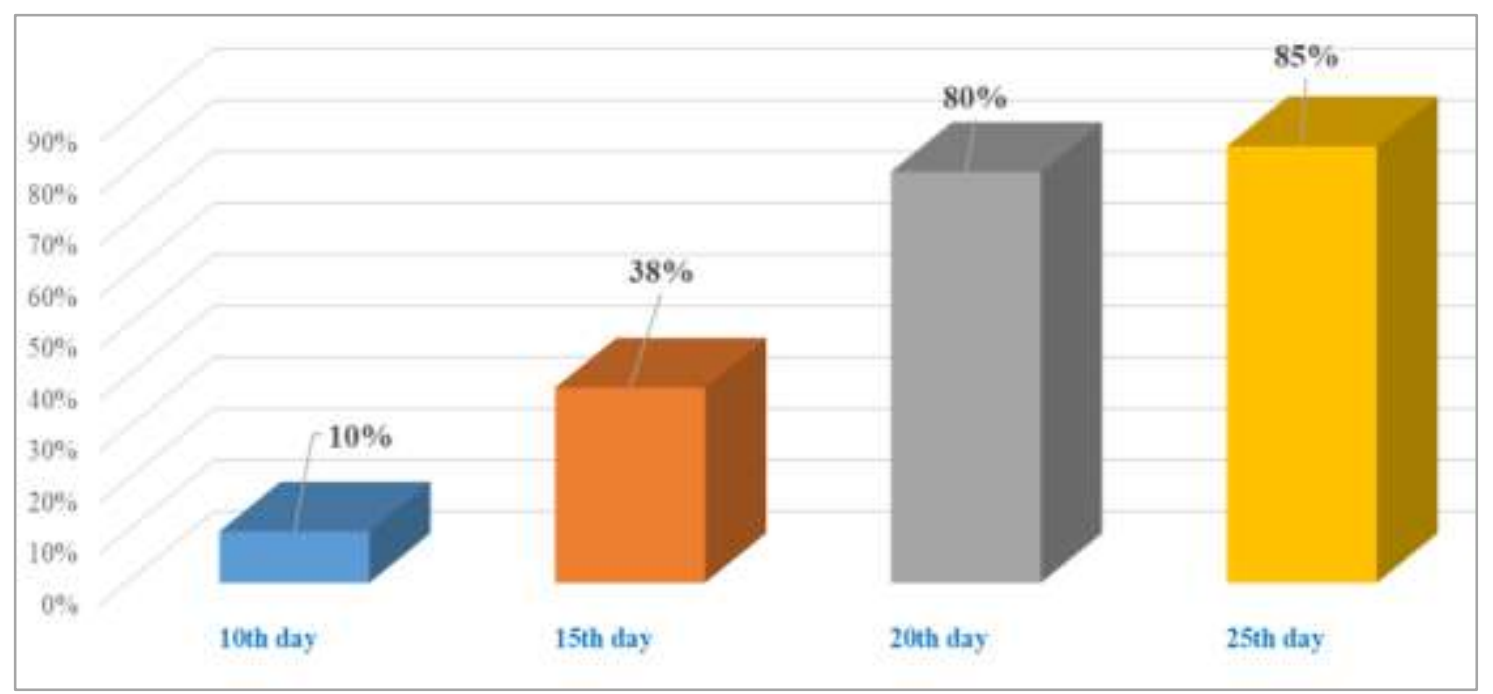

Fig. 2. Seeds germination in laboratory condition

Experiments have shown that the germination of seeds of salvia is satisfactory, averaging $80-85 \%$ under laboratory conditions $\left(18-20^{\circ} \mathrm{C}\right)$ (Fig. 1).

In order to determine the optimal sowing time of plant seeds in field conditions, experiments were conducted during the sowing seasons (spring and autumn), taking into account seed germination under laboratory conditions. To obtain accurate data, the seeds were tested by sowing in March-April and NovemberDecember months of the year. 
Table 1

Relations of seed germination with sowing time

\begin{tabular}{|c|c|c|c|}
\hline Sowing period & $\begin{array}{c}\text { Sowing time, } \\
\text { (month) }\end{array}$ & Sowing sates & Germination, \% \\
\hline \multirow{4}{*}{ Spring } & \multirow{2}{*}{ March } & 01.03 .15 & 85 \\
\cline { 2 - 4 } & \multirow{2}{*}{ April } & 15.03 .15 & 83 \\
\cline { 2 - 4 } & \multirow{2}{*}{ October } & 01.04 .15 & 80 \\
\cline { 2 - 4 } & & 15.04 .15 & 73 \\
\hline \multirow{3}{*}{ Autumn } & \multirow{2}{*}{ November } & 01.10 .15 & 73 \\
\cline { 2 - 4 } & & 15.10 .15 & 73 \\
\cline { 2 - 4 } & & 01.11 .15 & 81 \\
\hline
\end{tabular}

According to experiments, seed germination was recorded at around $75-80 \%$ in all sown variants. However, in early spring seed germination rate was higher in the seeds sown in the first days of March, which were reported to be relatively higher $(80-85 \%)$ than the germination rates observed under laboratory conditions.

For propagating from seeds, medicinal salvia plant seeds were sown at a depth of $2-3 \mathrm{~cm}$, making rows of 60-70 cm intervals in late March when the soil temperature was $12-15^{\circ} \mathrm{C}$ above 0 . Consumption of 7-8 $\mathrm{kg}$ of seeds of one class gave effective results per ha.

Grass biology. The sown seeds germinated in 1522 days and the seeds were observed to form leaves. The main root was 3,5-4 $\mathrm{mm}$ long and the total length of the grass was noted to be around $1-1,5 \mathrm{~cm}$. On the 10 $12^{\text {th }}$ days of observation, the length of the grass seed leaves was $2-4 \mathrm{~mm}$. It has been observed that since the grass period they have been covered with hairs. The main arrow root of the grass reached $1-2 \mathrm{~cm}$, and the lateral first-order side roots were $0,2-0,4 \mathrm{~mm}$. At this time it was observed that the total length of the plant reached 1,0-1,2 cm. When the appearance of the first true leaves was observed on the $12-15^{\text {th }}$ days of development, the upper part of the leaf blade was covered with small hairs. True leaf shape became elongated, $0,5 \mathrm{~mm}$ wide and $0,8 \mathrm{~mm}$ long. At this time it was found that the main root reached $4,5-5 \mathrm{~cm}$, the lateral roots reached $0,8-1 \mathrm{~cm}$. The grasses grew slowly and their total length made $3-3,8 \mathrm{~cm}$. In spring, as a result of rainfall, the formation cracked soil is observed in the areas planted with medicinal salvia plants. To remove the cracked formation and clods, inter-rows of plant were softened, mulched with wood chips and rotten manure, and at the same time thinned, leaving 2-3 plants every $20 \mathrm{~cm}$.

Observations showed that in the first growing year, the length of the main stem of the plant reached 20-28 $\mathrm{cm}$, the number of leaves reached 10-16. The woodiness of the lower part of the main stem was $3-5 \mathrm{~cm}$ and the number of leaves shed from this place averaged 4-6 pcs.
In the first growing year, the number of first-order branches reached 8-10 pcs, with a length of $15-17 \mathrm{~cm}$, and the number of leaves made $15-18$ pcs. The leaf blade was $8-10 \mathrm{~cm}$ long, $2-2,8 \mathrm{~cm}$ wide, and the length of petiole was $5-6,1 \mathrm{~cm}$.

\section{CONCLUSION}

Thus, scientific studies have shown that the medicinal salvia plant grows sufficiently in irrigated soils with high fertility and moderate mechanical content. Sowing the seeds of the plant in autumn and early spring gives effective results. No generative period was recorded in the first year of development when propagated from seed. It was noted that the preservation of grass seedlings grown at the end of the growing season is high, $70-80 \%$. At present, the necessary agrotechnical measures for this plant are being carried out on the experimental plots and various methods of propagation are being studied.

\section{REFERENCES}

1. Akhmedov U., Ergashev A., Ablazov A., Yulchieva M. (2009). Technology and ecology of growing medicinal plants. Tashkent, $178 \mathrm{p}$

2. Akopov I.E. (1990). The most important domestic medicinal plants and their use. Tashkent: Medicine, $444 p$.

3. Kholmatov Kh.Kh., Kosimov A.I. (1994). Medicinal plants. Tashkent: Ibn Sino publishing house, 217 p.

4. Murdakhaev Yu.M. (1993). Medicinal plants in Uzbekistan. Tashkent. "Fan". 39 p.

5. Nurmatov N. (2007). Methodology for field experiments. Tashkent, $149 \mathrm{p}$.

6. Presidential decree on "Strategy of Actions for further development of the Republic of Uzbekistan" numbered -4947 from February 7, 2017. Collection of legal documents of the Republic of Uzbekistan, 2017., the $6^{\text {th }}$ edition, article №70.

7. Toshmatova Z. (1978). Bioecological features of Salvia officinalis L. in Botanical Garden of the Academy of Sciences of the USSR. Introduction and acclimatization of plants. Tashkent: Fan, pp. 34-36. 
8. Tukhtaev B.Yo., Makhkamov T.X. (2015). Guidelines on establishing plantations of medicinal and food plants and preparation of their raw material. Tashkent, $106 \mathrm{p}$.

9. Turova A. Sapozhnikova E. (1982). Medicinal plants and their use, Moscow, pp. 39-40. 